\title{
Crescimento de frutos do meloeiro sob diferentes relações fonte:dreno
}

\author{
Tatiana da S Duarte'; Roberta MN Peil'² Eduardo M Montezano ${ }^{2}$ \\ ${ }^{1}$ UFPel-FAEM, Av. Itaimbé, 664B, apto. 302, 97050-330 Santa Maria-RS; ${ }^{2}$ UFPel-FAEM, Campus, 96010-900 Pelotas-RS; \\ agrotati@hotmail.com; rmpeil@ufpel.tche.br; montezano@via-rs.net
}

\begin{abstract}
RESUMO
Um experimento foi realizado em ambiente protegido, de setembro de 2004 a janeiro de 2005, para avaliar o efeito da densidade de plantio e do número de frutos por planta no aumento da biomassa de frutos de meloeiro cultivado em substrato de casca de arroz crua e fertirrigado com solução nutritiva recirculada. Três densidades de plantio $\left(1,7 ; 2,4\right.$ e 3,0 plantas $\left.\mathrm{m}^{-2}\right)$ e dois números de frutos por planta (3 e 4) foram estudados. A partir dos dados de matéria seca e fresca, aos 68 dias após o transplante, foram determinadas à produção e a distribuição de biomassa para os frutos. A matéria seca alocada nos frutos variou de 57 a $62 \%$ ao final do ciclo de cultivo, confirmando que, no meloeiro, estes são os maiores drenos de assimilados. A área foliar do meloeiro conduzido verticalmente e podado, ao final do cultivo, é relativamente baixa, o que associado a uma alta disponibilidade radiativa, evitou o excesso de sombreamento mútuo entre as plantas, mesmo na maior densidade de plantio. Assim, a maior densidade não afetou a distribuição de matéria seca e fresca para os frutos, aumentou a produção absoluta, por unidade de área, da biomassa da cultura e dos frutos. $\mathrm{O}$ aumento do número de frutos reduziu a matéria seca média dos frutos, sem afetar a produção e a distribuição de matéria seca total da planta e dos frutos. Entretanto, a produção e a distribuição de matéria fresca para os frutos assumem um comportamento diferente do da matéria seca, sendo ambas beneficiadas com tal incremento.
\end{abstract}

Palavras-chave: Cucumis melo, matéria seca, cultivo sem solo, carga de frutos, densidade de plantio.

\section{ABSTRACT \\ Fruit growth of melon plants submitted to different source:sink ratios}

An experiment was performed under protected environment from September/2004 to January/2005, to evaluate the effect of plant density and the number of fruits per plant on the growth of melon fruits cultivated in raw rice husk with recirculated nutrient solution. Three planting densities $\left(1,7 ; 2,4\right.$ and 3,0 plants $\left.\mathrm{m}^{-2}\right)$ and two number of fruits/plant ( 3 and 4) were studied. From the data of dry and fresh matter, 68 days after setting, the biomass production and distribution to the fruits was established. The fruits comprised from 57 to $62 \%$ of the total above-ground dry matter production, which demonstrated that they are the strongest sinks for assimilates in melon. At the end of the vegetative period, the melon plant leaf area, when trained vertically and pruned, is relatively low, which in association with a high solar radiation, avoids an excess of mutual shading among the plants, even at higher planting densities. Thus, the increase of planting density does not affect the distribution of dry and fresh matter to the fruits, increasing the absolute plant and fruit biomass production per square meter. The increment of the number of fruits reduced the average dry weight of the fruits, without affecting the production and the distribution of dry matter of the whole plant and fruits. However, the production and the distribution of fresh matter to the fruits take up a different behavior from that of the dry matter, being both benefited with such an increment.

Keywords: Cucumis melo, dry-matter, soilless cultivation, fruit load,

planting density.

(Recebido para publicação em 11 de setembro de 2007; aceito em 30 de julho de 2008)

$\mathrm{O}$ cultivo sem solo veio revolucionar a produção de hortaliças, principalmente, pela possibilidade de se ter um maior controle dos fatores de produção, particularmente, sobre a administração de água e nutrientes. Adicionalmente, os sistemas de cultivo sem solo apresentam uma alta eficiência, sobretudo aqueles que permitem a reutilização da solução nutritiva e o uso de substratos de fácil reciclagem.

A adoção de um novo sistema de produção exige conhecer o comportamento das culturas e determinar o manejo mais adequado à nova situação. É necessário, portanto, conhecer as relações que regem o funcionamento da planta e, em seguida, compreender a forma segundo a qual todas essas relações se encadeiam entre si para resultar no rendimento final.

O processo produtivo de uma cultura pode ser caracterizado através do seu crescimento, e este pode ser definido a partir da produção e distribuição da biomassa entre os diferentes órgãos da planta (Marcelis, 1993a). A distribuição da biomassa entre os órgãos da planta afeta a produção total e o peso individual de frutos, os quais são importantes determinantes do rendimento econômico das culturas (Peil \& Gálvez, 2002a). Essa distribuição, principalmente, da matéria seca entre os diferentes órgãos de uma planta, é o resultado final de um conjunto ordenado de processos metabólicos e de transporte que governam o fluxo de fotoassimilados através de um sistema fonte:dreno. O produtor tem interesse em que uma máxima proporção de assimilados seja destinada aos frutos. Não obstante, existem limites para a fração de assimilados que pode ser translocada para esses, já que as plantas necessitam destinar uma quantidade mínima para os demais órgãos, a fim de manter a sua capacidade produtiva (Peil \& Gálvez, 2005). Conseqüentemente, o balanço apropriado entre o aporte e a demanda de assimilados por uma planta tem grande importância para maximizar a produção. E pode ser manejada através de uma adequada relação fonte:dreno. Para maximizar a produção de frutos é necessário atingir a produção potencial de assimilados em nível da planta inteira e em seguida translocar para os frutos a maior fração 
possível desses assimilados.

Algumas práticas de manejo das culturas, como a variação da densidade de plantio (Heuvelink, 1997; Marcelis, 1996; Peil \& Gálvez, 2002b; Schvambach et al., 2002; Fagan, 2005) e do número de frutos por planta (Marcelis, 1993b; Heuvelink, 1995b; Valantin, 1999; Peil \& Gálvez, 2002b;), interferem no equilíbrio entre o crescimento dos compartimentos vegetativo e generativo da planta (fonte:dreno).

A relação fonte:dreno pode ser manipulada aumentando ou diminuindo a força de fonte (taxa fotossintética da cultura) ou a força de dreno (demanda por assimilados). A densidade de plantio afeta a penetração da radiação solar no dossel vegetal, a taxa fotossintética e o equilíbrio entre o crescimento da fração vegetativa e dos frutos. Modificações na eficiência das fontes a partir de uma elevação na população de plantas aumentam a produção de matéria seca da cultura, apresentando um efeito indireto de redução da fração de matéria seca distribuída para os frutos de plantas de tomate (Heuvelink, 1995b) e de pepino (Schvambach et al., 2002; Peil \& Gálvez, 2002b). Um incremento no número de frutos de tomate e de pepino aumenta a fração de biomassa alocada nestes em detrimento da fração vegetativa, mas diminui a fração para cada dreno generativo considerado individualmente (Heuvelink, 1997; Marcelis, 1992). Assim, aumentando-se o número de frutos por planta, a demanda de fotoassimilados por esses se eleva, instalando-se uma forte competição por assimilados entre os frutos.

Quanto à cultura do meloeiro, há evidências que indicam (Duarte, 2006) que a variação do número de frutos exerce efeito diferenciado sobre a translocação de biomassa para os frutos. Quanto à densidade de plantio poucas referências existem sobre se o efeito da variação desta prática se manifesta de maneira semelhante ao das culturas citadas.

Devido ao grande tamanho dos frutos e sua elevada capacidade de estocagem de assimilados, o índice de pegamento e o consequiente número de frutos fixados/planta é baixo. Portanto, supõe-se que os efeitos da variação das referidas práticas possam ser modificados. Neste trabalho procurou-se gerar conhecimento sobre o crescimento dos frutos, observando a influência do aumento da densidade de plantio e da variação do número de frutos por planta sobre a produção e a distribuição de biomassa para os frutos do meloeiro, cultivado em substrato de casca de arroz com recirculação dos lixiviados.

\section{MATERIAL E MÉTODOS}

O experimento foi conduzido em uma estufa modelo "Arco Pampeana”, revestida com filme de polietileno de baixa densidade, compreendendo uma área de $210 \mathrm{~m}^{2}$, disposta no sentido Norte-Sul e localizada no Campus Universitário da UFPel (latitude 31 ${ }^{\circ} 52^{\prime}$ S, longitude $52^{\circ} 21^{\prime} \mathrm{W}$ e altitude $13 \mathrm{~m}$ ). Em 29/09/04, efetuou-se a semeadura da cultivar de meloeiro tipo gália "Hales Best Jumbo" (Cucumis melo var. reticulatus), em bandejas de poliestireno com 72 células, contendo como substrato vermiculita, em um sistema de bandejas flutuantes. A solução nutritiva usada para a produção das mudas foi a mesma recomendada para o cultivo definitivo, porém, na concentração de $50 \%$ (condutividade elétrica inicial de 0,81 $\mathrm{dS} \mathrm{m} \mathrm{m}^{-1}$ ).

Aos 35 dias após a semeadura, as mudas ( 5 folhas definitivas) foram transplantadas individualmente para sacos plásticos perfurados na base para permitir a drenagem, contendo cada uma, $13 \mathrm{~L}$ de casca de arroz crua.

Doze canais $(7,5 \times 0,37 \mathrm{~m}$ e $2 \%$ de declividade) foram dispostos em seis linhas duplas, com distância interna de $0,50 \mathrm{~m}$ e passeio de $1,19 \mathrm{~m}$. Os sacos de cultivo foram arranjados nos canais, revestidos com filme de polietileno dupla face, de maneira a formar canais impermeáveis fechados sobre os sacos de cultivo. Um tanque de armazenamento da solução nutritiva foi enterrado próximo à extremidade de cota menor, ao final de cada linha dupla de canais. Um conjunto moto-bomba (1/4HP) em cada tanque impulsionava a solução para a cota maior do canal através de um cano de PVC de $25 \mathrm{~mm}$. A partir deste ponto, a solução foi fornecida às plantas por meio de uma mangueira de polietileno de $1 / 2$ polegada, perfurada para a colocação de dois espaguetes por saco.

O sistema de condução das plantas foi adaptado de Cermeño (1996). As plantas foram conduzidas tutoradas, com uma haste única e despontadas ao alcançar o arame dos tutores (3,5 $\mathrm{m}$ do solo). Somente após a oitava axila, permitiu-se o crescimento de hastes secundárias e a partir da décima segunda, o desenvolvimento dos frutos. Estas hastes foram despontadas uma folha após a flor hermafrodita. $\mathrm{O}$ raleio dos frutos foi feito logo após a antese das flores hermafroditas, conforme o tratamento utilizado, respeitando-se uma determinada distância entre os frutos deixados na planta (aproximadamente 3 a 4 hastes secundárias entre os frutos).

A solução nutritiva foi monitorada diariamente através das medidas de condutividade elétrica e de $\mathrm{pH}$. A reposição de nutrientes ou de água foi realizada através da adição de soluções estoques concentradas ou de água, quando o valor da condutividade elétrica sofreu, respectivamente, uma diminuição ou um aumento, da ordem de $15 \%$. O pH da solução nutritiva foi mantido entre 6,0 e 7,0 através da adição de solução de correção com ácido nítrico $\left(\mathrm{HNO}_{3} 1 \mathrm{~N}\right)$.

As plantas foram fertirrigadas através de um fluxo intermitente, programado por um temporizador em 8 intervalos de tempo pré-estabelecidos. A vazão média diária por planta foi estabelecida conforme a fase de desenvolvimento com base em dados de consumo d'água e coeficiente de cultura do meloeiro cultivado em ambiente protegido (Caron, 1999), mais 20\% de solução nutritiva para drenagem, resultando em $0,47 \mathrm{~L}_{\text {planta }}{ }^{-1}$ na fase inicial (crescimento vegetativo até o início do florescimento); 1,37 L planta ${ }^{-1}$ na segunda fase (crescimento vegetativo, florescimento e frutificação inicial); 2,24 $\mathrm{L}_{\text {planta }}{ }^{-1}$ na terceira fase (crescimento dos frutos) e 2,16 $\mathrm{L}_{\text {planta }}{ }^{-1}$ durante a última fase (maturação dos frutos).

A solução nutritiva empregada foi a recomendada por Castro (1999) para a cultura do meloeiro em substratos, com condutividade elétrica inicial de 2,3 dS 
Tabela 1. Efeito da densidade de plantio e do número de frutos por planta sobre as matérias seca e fresca acumuladas pela planta ${ }^{1}$ e pelos frutos por unidade de superfície (aos 68 dias após o transplante) e sobre a relação de matéria dos frutos / matéria da planta (effect of plant density and the number of fruits per plant on the total dry and fresh matter accumulated by plant ${ }^{1}$ and fruits for square meter (68 days after setting) and on the matter of fruits/matter of plant ratio). Pelotas, UFPel, 2004.

\begin{tabular}{|c|c|c|c|c|c|c|c|c|}
\hline \multirow[b]{2}{*}{ Efeito } & \multicolumn{4}{|c|}{ Matéria seca } & \multicolumn{4}{|c|}{ Matéria fresca } \\
\hline & $\begin{array}{l}\text { Planta } \\
\left(\mathrm{g} \mathrm{m}^{-2}\right)\end{array}$ & $\begin{array}{l}\text { Frutos } \\
\left(\mathrm{g} \mathrm{m}^{-2}\right)\end{array}$ & $\begin{array}{c}\text { Relação } \\
\text { fruto/planta } \\
\left(\mathbf{g ~ g ~ g}^{-1}\right)\end{array}$ & $\begin{array}{l}\text { Peso médio } \\
\text { de frutos }(\mathrm{g})\end{array}$ & $\begin{array}{l}\text { Planta } \\
\left(\mathrm{g} \mathrm{m}^{-2}\right)\end{array}$ & $\begin{array}{l}\text { Frutos } \\
\left(\mathrm{g} \mathrm{m}^{-2}\right)\end{array}$ & $\begin{array}{c}\text { Relação } \\
\text { fruto/planta } \\
\left(\mathbf{g ~ g}^{-1}\right)\end{array}$ & $\begin{array}{l}\text { Peso médio } \\
\text { de frutos }(\mathrm{g})\end{array}$ \\
\hline \multicolumn{9}{|c|}{$\begin{array}{l}\text { Densidade de } \\
\text { plantio } \\
\text { (plantas } \mathrm{m}^{-2} \text { ) }\end{array}$} \\
\hline 1,7 & $698,5 \quad c^{2}$ & $422,0 \mathrm{~b}$ & $0,60 a$ & 71,8 a & $9592,9 \mathrm{c}$ & $7062,0 \mathrm{~b}$ & $0,74 a$ & 1181,9 a \\
\hline 2,4 & $876,5 \mathrm{~b}$ & $499,2 \mathrm{~b}$ & $0,57 a$ & $69,1 \mathrm{a}$ & $12412,7 b$ & $8811,2 b$ & $0,71 \mathrm{a}$ & 1121,0 a \\
\hline 3,0 & $1146,5 \mathrm{a}$ & 713,9 a & $0,62 \mathrm{a}$ & $60,3 a$ & $16007,4 \mathrm{a}$ & $11695,4 \mathrm{a}$ & $0,73 a$ & 1065,5 a \\
\hline \multicolumn{9}{|c|}{$\begin{array}{l}\text { Número de } \\
\text { frutos planta- }\end{array}$} \\
\hline 3 & 888,7 a & 522,6 a & $0,59 a$ & $73,8 \mathrm{a}$ & $11757,0 \mathrm{~b}$ & 8301,4 b & $0,71 \mathrm{a}$ & $1166,1 \mathrm{a}$ \\
\hline 4 & 925,6 a & 567,4 a & $0,61 \mathrm{a}$ & $60,4 \mathrm{~b}$ & $13519,4 \mathrm{a}$ & 9986,8 a & $0,74 \mathrm{a}$ & 1049,4 a \\
\hline
\end{tabular}

${ }^{1}$ Matéria da planta corresponde à parte aérea (folhas + caule + pecíolos + frutos); ${ }^{2}$ Médias seguidas pelas mesmas letras nas colunas, dentro de cada fator, não diferem significativamente pelo teste de Duncan $(\mathrm{p} \leq 5 \%)\left({ }^{1}\right.$ total plant matter represented by leaves + stem + petioles + fruits; ${ }^{2}$ means followed by the same letters in the column did not differ from each other; Duncan, $5 \%$ )

$\mathrm{m}^{-1}$. Os macronutrientes seguem a seguinte composição $(\mathrm{em} \mathrm{mmol} \mathrm{L-1}): 12,64$ de $\mathrm{NO}_{3}^{-} ; 1,25$ de $\mathrm{H}_{2} \mathrm{PO}_{4}^{-} ; 1,15$ de $\mathrm{SO}_{4}^{-2}$; $0,7 \mathrm{de}_{4}^{++} ; 5,5$ de $\mathrm{K}^{+} ; 4,0 \mathrm{de} \mathrm{Ca}^{2+}$ e 1,0 de $\mathrm{Mg}^{2+}$. E, os micronutrientes (em $\mathrm{mg}$ $\left.\mathrm{L}^{-1}\right): 4,0$ de Fe; 0,56 de $\mathrm{Mn} ; 0,26$ de $\mathrm{Zn}$; 0,03 de $\mathrm{Cu} ; 0,22$ de $\mathrm{Mo} \mathrm{e} 0,05$ de $\mathrm{B}$.

Estudou-se os fatores experimentais densidade de plantio $(1,7 ; 2,4$; e 3,0 plantas $\mathrm{m}^{-2}$, distanciadas na linha a 0,$7 ; 0,5 \mathrm{e}$ $0,4 \mathrm{~m}$, respectivamente) e número de frutos por planta ( 3 e 4 frutos planta ${ }^{-1}$ ). $\mathrm{O}$ delineamento experimental adotado foi inteiramente casualizado no esquema de parcelas subdivididas (parcela para densidade de plantio e subparcela para número de frutos), com 3 repetições. Cada parcela foi constituída por 20 plantas e a subparcela por 10 plantas.

Avaliou-se a matéria fresca e a seca acumulada ao final do experimento, 68 dias após o transplante, incluindo os frutos colhidos e as podas realizadas durante o cultivo. Pesaram-se as plantas, separadamente, em três frações: folhas, caules e frutos, para a determinação da matéria fresca. Após, procedeu-se a secagem em estufa a $65^{\circ} \mathrm{C}$, até peso constante, para a obtenção da matéria seca. A biomassa total correspondeu à soma das folhas, caules e frutos, e a biomassa vegetativa, à soma das folhas e caules. Com base nesses dados, estabeleceu-se a produção e a distribuição de matéria fresca e seca entre os diferentes órgãos da planta. O período de crescimento (da antese à colheita) e o peso seco e fresco individual de frutos fixados no ramo secundário da décima terceira axila foliar foram registrados em 3 plantas por tratamento, para a determinação da taxa de crescimento de frutos individuais. Os resultados foram submetidos à análise de variância e as médias testadas pelo teste de Duncan, a 5\% de probabilidade.

\section{RESULTADOS E DISCUSSÃO}

Não houve interação entre os fatores densidade de plantio e número de frutos $(\mathrm{p} \leq 5 \%)$.

A matéria seca alocada nos frutos variou de 57 a $62 \%$ ao final do ciclo de cultivo, confirmando que estes são, no meloeiro, os mais potentes órgãos drenos de assimilados. As percentagens médias alcançadas neste trabalho são comparáveis às obtidas por outros autores para a cultura do meloeiro, variando de 50 a 66\% (Valantin et al., 1999; Fagan, 2005; Duarte, 2006).

Efeito da Densidade de plantio $\mathrm{O}$ aumento da densidade de plantio incrementou a matéria seca e fresca total das plantas por unidade de área, enquanto que para matéria seca e fresca dos frutos a maior resposta ocorreu a partir da densidade de 2,4 plantas $\mathrm{m}^{-2}$ (Tabela 1). A maior produção de matéria seca total estaria relacionada com uma maior quantidade total de energia solar interceptada pelo dossel mais adensado, nessa mesma unidade de área, sugerindo uma superior força de fonte do conjunto de plantas na maior densidade e, assim, beneficiando a produção de matéria seca e fresca das plantas e dos frutos, conforme relatado por Papadoupoulos \& Pararajasingham (1996) para a cultura do tomateiro e observado para a cultura do pepino por Peil (2000).

A distribuição de matéria seca e fresca para os frutos (dada pela relação de matéria de frutos/matéria da planta) não foi afetada pela variação da força de fonte a partir da densidade de plantio (Tabela 1). Esse resultado não era esperado, pois essa prática, normalmente, interfere no equilíbrio entre o crescimento vegetativo e o reprodutivo da planta, já que afeta a penetração da radiação solar no interior do dossel vegetativo. Modificações na força das fontes, através de uma alteração na densidade de plantas ou do aumento da disponibilidade de radiação, afetariam indiretamente a distribuição de matéria seca entre os órgãos da planta. O maior sombreamento mútuo e, conseqüentemente, a menor força de fonte individual das plantas mais altas reduziria a disponibilidade de fotoassimilados para o crescimento dos frutos, diminuindo a força de dreno do compartimento 
generativo, o que levaria a uma redução da proporção de matéria seca translocada para este. No entanto, para o meloeiro cultivado nas condições do presente trabalho, o aumento da densidade de plantio parece não ter afetado a força individual de fonte de cada planta, pois não diminuiu a translocação de biomassa para os frutos (Tabela 1), diferentemente do verificado por outros autores para o tomateiro (Heuvelink, 1995a, 1995b; Papadopoulos \& Pararajasingham, 1996) e para o pepino (Marcelis, 1993b, 1996; Peil \& Gálvez, 2002b; Schvambach et al., 2001), que apresentaram uma redução na força de fonte (menor produção absoluta de matéria seca vegetativa da planta) na maior densidade de plantio. Para essas culturas, à escala da planta, pelo maior sombreamento que ocorre na maior densidade, há uma redução da força de fonte e da disponibilidade de fotoassimilados, reduzindo a proporção com que estes são destinados aos frutos, em benefício da fração destinada aos órgãos vegetativos. A menor disponibilidade de fotoassimilados por planta vai refletir-se em um maior índice de abortos e em um menor crescimento dos frutos. No presente trabalho, o índice de abortos não foi verificado, já que o número de frutos por planta foi pré-estabelecido. No entanto, não houve problemas na fixação de frutos nos diferentes tratamentos o que, aliado aos similares teores de matéria seca da parte vegetativa e dos frutos (Tabela 2), indica que as maiores densidades não diminuíram a disponibilidade de assimilados para os órgãos vegetativos e os frutos.

A alta e crescente disponibilidade de radiação solar do período de primavera e inicio de verão $\left(1433,1 \mathrm{MJ} \mathrm{m}^{-2}\right.$ de radiação solar global exterior), no qual se desenvolveu o experimento, associada a uma maior radiação solar refletida favorecida pelo piso branco da estufa (Gijzen, 1995), assim como, às características da planta do meloeiro, como o baixo índice de área foliar (IAF), colaboraram para os resultados obtidos no presente trabalho. Para as culturas do tomateiro e do pepino em ambiente protegido, o IAF alcança, normalmente, valores superiores a 3,0 ao final do cultivo, podendo inclusive chegar a valores superiores a 5,0-6,0 (Acock et al.,

Tabela 2. Efeito da densidade de plantio e do número de frutos por planta sobre o teor de matéria seca (\% do peso fresco) dos frutos e da fração vegetativa ${ }^{1}$ (effect of plant density and the number of fruits per plant on the dry-matter percentage (\% of cumulative fresh weight) of the fruits and vegetative parts). Pelotas, UFPel, 2004.

\begin{tabular}{ccc}
\hline \multirow{2}{*}{ Efeito } & \multicolumn{2}{c}{ Teor de matéria seca (\%) } \\
\cline { 2 - 3 } & Frutos & Fração vegetativa \\
\hline $\begin{array}{c}\text { Densidade de plantio } \\
\left.\text { (plantas } \mathbf{~ m}^{-2}\right)\end{array}$ & & \\
\cline { 2 - 3 } 1,7 & $6,0 \mathrm{a}^{2}$ & $10,9 \mathrm{a}$ \\
2,4 & $5,7 \mathrm{a}$ & $10,5 \mathrm{a}$ \\
3,0 & $6,1 \mathrm{a}$ & $10,1 \mathrm{a}$ \\
\hline Número de frutos planta- & & \\
3 & $6,3 \mathrm{a}$ & $10,6 \mathrm{a}$ \\
4 & $5,7 \mathrm{~b}$ & $10,3 \mathrm{a}$ \\
\hline
\end{tabular}

${ }^{1}$ Matéria da fração vegetativa corresponde à soma: folhas + caule + pecíolos; ${ }^{2}$ Médias seguidas pelas mesmas letras nas colunas, dentro de cada fator, não diferem significativamente pelo teste de Duncan $(\mathrm{p} \leq 5 \%)\left({ }^{1}\right.$ matter of vegetative parts represented by leaves + stem + petioles; ${ }^{2}$ means followed by the same small letter in the column did not differ from each other; Duncan, 5\%)

1978; Peil, 2000). Enquanto que para o meloeiro conduzido verticalmente e podado, ao final do cultivo, o IAF alcança valores bem inferiores ao destas culturas. Os IAF obtidos no presente trabalho foram de 1,$60 ; 2,75$ e 2,63 para 1,$7 ; 2,4$ e 3,0 plantas $\mathrm{m}^{-2}$, respectivamente. Outros autores encontraram valores de IAF bastante baixos para a cultura, conduzida tutorada, em comparação ao tomateiro e ao pepino, não passando de 2,5 (Andriolo et al., 2003; Bacchi, 2004; Andriolo et al., 2005; Fagan, 2005). Este comportamento deve-se, principalmente, à menor área individual de suas folhas em comparação ao tomateiro e ao pepino, o que aliado à alta disponibilidade radiativa do período levou com que o efeito do maior sombreamento mútuo na maior densidade de plantio fosse diluído, favorecendo uma similaridade na disponibilidade de fotoassimilados e, conseqüientemente, similaridade na distribuição destes para os frutos.

Uma tendência de redução do peso seco e fresco de frutos individuais com o aumento da densidade de plantio foi verificada no presente trabalho (Tabela 3), em decorrência de uma tendência de redução na taxa de crescimento obtida por esses frutos nas maiores densidades de plantio. Resultados semelhantes foram obtidos por Paris et al. (1988), os quais conduziram experimentos em Israel e na Flórida, obtendo com o aumento da densidade de plantio uma queda no peso médio individual de frutos em ambos os locais. Porém o número e a produção de frutos por unidade de área cultivada não foram afetados na Flórida, enquanto que em Israel houve um aumento significativo dessas variáveis.

Efeito do número de frutos por planta - A produção de matéria seca total da planta e dos frutos por unidade de área, bem como a distribuição de assimilados para os frutos não foram afetados pelo aumento de três para quatro no número de frutos por planta (Tabela 1). Segundo Heuvelink (1995a), a distribuição de assimilados para os frutos depende fortemente do número desses na planta. Tais resultados diferem daqueles obtidos para outras hortaliças de fruto, principalmente no que se refere à distribuição de matéria seca para os frutos. Em outras hortaliças de frutos cultivadas em ambiente protegido, a proporção de distribuição de assimilados entre os diferentes órgãos da planta, sofre regulação pelos próprios drenos. Assim, a distribuição de matéria seca para os frutos estaria relacionada com a carga de frutos (número ou matéria total de frutos por planta), havendo um aumento da distribuição de assimilados para os frutos quando aumenta-se o número desses, conforme observado para o tomateiro (Heuvelink, 1997; Heuvelink, 1995a) e para o pepino (Marcelis, 1996; Peil \& Gálvez, 2002a). Deve-se ter em conta que os frutos de meloeiro, quando analisados individualmente (Tabela 
Tabela 3. Efeito da densidade de plantio e do número de frutos por planta sobre o período de crescimento (da antese até a colheita), as matérias seca e fresca na colheita e a taxa de crescimento médio de frutos localizados no ramo secundário da décima terceira axila foliar (effect of plant density and the number of fruits per plant on the growing period from anthesis until harvest, the harvest matter and the average growth rate of the fruit of the $13^{\text {th }}$ leaf axil of secondary stems). Pelotas, UFPel, 2004.

\begin{tabular}{|c|c|c|c|c|c|}
\hline \multirow[b]{2}{*}{ Efeito } & \multirow[b]{2}{*}{$\begin{array}{l}\text { Período de } \\
\text { crescimento } \\
\text { (dias) }\end{array}$} & \multicolumn{2}{|c|}{ Matéria seca } & \multicolumn{2}{|c|}{ Matéria fresca } \\
\hline & & $\begin{array}{c}\text { Peso } \\
\text { individual (g) }\end{array}$ & $\begin{array}{c}\text { Taxa de } \\
\text { crescimento } \\
\left(\text { g dia }^{-1}\right)\end{array}$ & $\begin{array}{c}\text { Peso } \\
\text { individual (g) }\end{array}$ & $\begin{array}{c}\text { Taxa de } \\
\text { crescimento } \\
\left(\mathrm{g} \mathrm{dia}^{-1}\right)\end{array}$ \\
\hline \multicolumn{6}{|c|}{$\begin{array}{l}\text { Densidade de } \\
\text { plantio } \\
\left(\text { plantas } \mathrm{m}^{-2} \text { ) }\right.\end{array}$} \\
\hline 1,7 & $30,2 a^{1}$ & 82,6 a & $2,74 \mathrm{a}$ & $1372,0 \mathrm{a}$ & 45,4 a \\
\hline 2,4 & $28,7 \mathrm{a}$ & $70,9 a b$ & $2,47 \quad b$ & $1200,9 a b$ & $41,8 \quad b$ \\
\hline 3,0 & $28,5 \mathrm{a}$ & $58,8 \quad b$ & $2,06 \quad b$ & $1078,2 \quad b$ & $37,8 \quad b$ \\
\hline \multicolumn{6}{|c|}{$\begin{array}{c}\text { Número de } \\
\text { frutos planta-1 }^{-1}\end{array}$} \\
\hline 3 & 29,9 a & $72,9 \mathrm{a}$ & $2,44 a$ & $1228,4 \mathrm{a}$ & $41,1 \mathrm{a}$ \\
\hline 4 & $28,3 \mathrm{a}$ & $68,7 \mathrm{a}$ & $2,43 \mathrm{a}$ & 1205,9 a & $42,6 a$ \\
\hline
\end{tabular}

${ }^{1}$ Médias seguidas pelas mesmas letras nas colunas, dentro de cada fator, não diferem significativamente pelo teste de Duncan $(\mathrm{P} \leq 5 \%)$ ( ${ }^{1}$ means followed by the same letters in the column did not differ from each other; Duncan, $5 \%)$.

3), em comparação com os frutos de tomateiro (Heuvelink, 1997) e de pepino (Marcelis, 1993b; Peil \& Gálvez, 2002a), possuem um peso muito superior e uma força de dreno (dada pela taxa de crescimento de frutos) (Tabela 3) muito mais elevada. Essas confirmações sugerem que para esta cultura e cultivar, dentro da faixa de 3 a 4 frutos planta $^{-1}$, há uma redução proporcional no peso médio de frutos ao aumentar-se o número desses, o que manteria a biomassa total dos frutos na planta similar nos dois níveis de número de frutos estudados, resultando numa similaridade de produção e distribuição de matéria seca entre a parte vegetativa e a generativa. Apesar de, para as culturas do tomateiro (Heuvelink, 1997) e do pepino (Peil \& Gálvez, 2002a), ocorrer também uma redução do peso médio do fruto ao aumentar-se o número desses, tal redução não mantém uma proporcionalidade tão próxima quanto no meloeiro (Tabela 1). Resultados semelhantes de redução do peso médio de frutos devido a um incremento do número de frutos por planta foram obtidos por Barni et al. (2003).

As taxas de crescimento do peso seco de frutos individuais (Tabela 3), obtidas no presente trabalho, são dados bastante interessantes para explicar a força de dreno dos frutos do meloeiro, já que esta é entendida como a velocidade de mudança de peso do órgão (Bertin \& Heuvelink, 1993). Quando a oferta de fotoassimilados é insuficiente para suprir o crescimento potencial de todos os órgãos, uma competição se estabelece e a repartição dos assimilados depende da força de dreno de cada órgão (Bertin \& Heuvelink, 1993). A força de dreno de um órgão refere-se ao seu tamanho. Um órgão teria uma força de dreno tanto maior quanto maior for a sua capacidade de estocagem (Andriolo, 1999). No caso do meloeiro, a força de dreno de um fruto individual é muito superior a da maioria das hortaliças de frutos, pois enquanto um fruto pode acumular em média 2,4 $\mathrm{g}_{\text {dia }}{ }^{-1}$ de matéria seca, o fruto do tomateiro acumula em média 0,129 $\mathrm{g} \mathrm{dia}^{-1}$ (Heuvelink, 1997) e o do pepino tipo longo 1,24 $\mathrm{g} \mathrm{dia}^{-1}$ (Peil \& Gálvez, 2002a). Confirma-se, assim, a alta potência de dreno dos frutos do meloeiro. Sugere-se que a fração da matéria seca repartida para os frutos do meloeiro apresenta um limite de saturação para um número de frutos por planta bastante inferior ao tomateiro, no qual a saturação seria atingida para uma carga superior a 45 frutos planta $^{-1}$ (Heuvelink, 1997). Provavelmente, as cargas de frutos trabalhadas no presente trabalho ultrapassaram o limite de saturação para a cultura do meloeiro. Por outro lado, possivelmente, a disponibilidade de assimilados providos pelas fontes (devido à grande disponibilidade de radiação solar do período) foi adequada para a produção de frutos do meloeiro nas condições de realização desse trabalho.

$\mathrm{O}$ aumento do número de frutos por planta promoveu uma maior produção e distribuição de matéria fresca para os frutos ao final do cultivo, diferentemente do que ocorreu com a matéria seca (Tabela 1). Geralmente, a matéria fresca segue o mesmo comportamento da matéria seca. Porém, a relação entre o crescimento da matéria fresca e a seca, a qual determina o teor de matéria seca, é pouco esclarecida. Evidências, coincidentes com as obtidas no presente trabalho, de que a quantidade de água acumulada pode ser independente da acumulação de matéria seca $(H o, 1987)$ e de que a demanda por água aumenta devido à maior quantidade de drenos (Fagan, 2005), foram registradas. Resultado semelhante foi obtido por Duarte (2006).

$\mathrm{A}$ adoção de um maior número de frutos (4 frutos planta ${ }^{-1}$ ) promoveu uma redução no teor de matéria seca dos frutos, sem afetar o teor de matéria seca da parte vegetativa (Tabela 2). Nesse caso, houve uma menor concentração de fotoassimilados nos frutos (i.e. maior produção de matéria fresca por grama de matéria seca), confirmando que, aumentando-se o número de frutos por planta, aumenta-se a competição por assimilados entre os frutos, sem afetar a fração vegetativa. Um reduzido teor de matéria seca afeta desfavoravelmente a qualidade dos frutos, indicando uma possível menor concentração de sólidos solúveis (açucares).

Conforme a Tabela 3, a matéria seca e fresca dos frutos localizados no ramo secundário da 13ª axila foliar não sofreram efeito do número de frutos. Em geral, o peso de frutos individuais aumenta com a redução do número de frutos (Heuvelink, 1997). Os frutos individuais avaliados foram os primeiros fixados na planta, quando a competição entre frutos ainda é praticamente inexistente. A similaridade obtida entre os pesos médios frescos de fruto ao final do experimento (Tabela 1), indica que a diferença no acúmulo de matéria fresca aumen- 
ta com o decorrer do ciclo de cultivo e o aumento gradativo do número de frutos na planta. Porém, um estudo mais detalhado é necessário para elucidar esse comportamento.

Segundo De Koning (1994), o período de crescimento de frutos é pouco influenciado pela relação fonte:dreno para o tomateiro. Entretanto, Peil \& Gálvez (2002a) encontraram um decréscimo no período de crescimento de frutos de pepino em plantas conduzidas com menor número de frutos, assim como, um maior peso individual de frutos na colheita.

Muitos drenos limitam o crescimento de frutos, porém esse efeito é reduzido quando não há radiação limitante (Heuvelink, 1995a). O aumento do número de frutos não afetou o crescimento destes, sobretudo em termos de matéria seca, o que se deveu ao período de realização do ensaio (primavera-verão), no qual não houve limitação de radiação solar. Para esse período, há um aumento na integral de radiação solar diária, o que proporciona maior atividade de fonte e, consequientemente, permitiu maior número de drenos.

No presente trabalho conclui que a área foliar do meloeiro ao final do cultivo é relativamente baixa o que, associado a uma alta disponibilidade de radiação solar, evita um excesso de sombreamento mútuo entre as plantas, mesmo na densidade de plantio mais elevada. Assim, o aumento da densidade de plantio não afetou a distribuição de matéria seca e fresca para os frutos, aumentando a produção absoluta, por unidade de área, de biomassa da cultura e dos frutos, quando não há limitação de radiação solar. O incremento do número de frutos reduziu o seu peso seco médio, sem afetar a produção e a distribuição de matéria seca total da planta e dos frutos. Entretanto, a produção e a distribuição de matéria fresca para os frutos assumem um comportamento diferente do da matéria seca, sendo beneficiadas com tal incremento.

Partindo dessas considerações e tendo em vista o menor tamanho médio de frutos, atualmente exigido pelo mercado consumidor, pode-se recomendar a densidade de 3 plantas $\mathrm{m}^{-2}$ e a fixação de 4 frutos por planta para a cultura do meloeiro cultivado em substrato de casca de arroz crua durante o período de primavera-verão.

\section{REFERÊNCIAS}

ACOCK B; CHARLES-EDWARDS DA; FITTER DJ; HAND DW; LUDWING J; WARREN-WILSON J; WITHERS AC. 1978. The contribution of leaves from different levels within a tomato crop to canopy net photosynthesis: an experimental examination of two canopy models. Journal of Experimental Botany 29: 815-827.

ANDRIOLO JL. 1999. Fisiologia das culturas protegidas. Santa Maria: UFSM. $142 \mathrm{p}$.

ANDRIOLO JL; LANZANOVA ME; WITTER M. 2003. Produtividade de frutos de meloeiro cultivado em substrato com três soluções nutritivas. Horticultura Brasileira 21: 478481.

ANDRIOLO JL; LUZ GL; BORTOLOTTO OC; GODOI RS. 2005. Produtividade e qualidade de frutos de meloeiro cultivado em substrato com três doses de solução nutritiva. Ciência Rural 35: 781-787.

BACCHI S. 2004. Crescimento, eficiência no uso da água e dos nutrientes e relações de contaminação do meloeiro cultivado em substrato de casca de arroz. Pelotas: UFPelFAEM, 65p. (Tese).

BARNI V; BARNI NA; SILVEIRA JRP. 2003. Meloeiro em estufa: duas hastes é o melhor sistema de condução. Ciência Rural 33: 10391043.

BERTIN N; HEUVELINK E. 1993. Dry-matter production in a tomato crop: comparison of two simulation models. J. Hortic. Sci. 68: 9951011.

CASTRO AC. 1999. Formulación de la solución nutritiva. Parámetros de ajuste. In: MILAGROS MF; GÓMEZ IMC. (Ed.). Cultivos sin suelo II. Almería: DGIFA-FIAPACaja Rural de Almería. 2ed. p. 257-266.

CARON BO. 1999. Consumo d'água e coeficiente de cultura do meloeiro cultivado em estufa plástica. Santa Maria: UFSM. 71p. (Tese mestrado)

CERMEÑO ZS. 1996. Veinte cultivos de hortalizas en invernadeiros. Sevilla: Spain, $639 \mathrm{p}$.

DE KONING ANM. 1994. Development and dry matter distribution in glasshouse tomato: a quantitative approach. Wageningen: Agricultural University. 240p. (Tese)

FAGAN EB. 2005. Regime de irrigação e densidade de frutos na produção do melão hidropônico. Santa Maria: UFSM. 60p. (Tese).

GIJZEN H. 1995. CO 2 uptake by the crop. Shortterm crop responses. Crop growth. In: BAKKER JC; BOT GPA; CHALLA H; VAN DE BRAAK NJ. Greenhouse climate control:an integrated approach. Wageningen Press: Wageningen, p.16-35.
HEUVELINK E. 1997. Effect of fruit load on dry matter partitioning in tomato. Scientia Horticulturae 69: 51-59.

HEUVELINK E. 1995a. Influence of sink-source interation on dry matter production in tomato. Annals of Botany 75: 381-389.

HEUVELINK E. 1995b. Effect of plant density on biomass allocation to the fruits in tomato (Lycopersicum esculentum Mill). Scientia Horticulturae 64: 193-201.

HO 1C; GRANGE RI; PICKEN AJ. 1987. An analysis of the accumulation of water ans dry matter in tomato fruit. Plant Cell Environ 10: 157-162.

MARCELIS LFM. 1992. The dynamics of growth and dry matter distribution in cucumber. Annals of Botany 69: 487-492.

MARCELIS LFM. 1993a. Simulation of biomass allocation in greenhouse crops: a review. Acta Horticulturae p. 49-67.

MARCELIS LFM. 1993b. Fruit growth and biomass allocation to the fruits in cucumber. Scientia Horticulturae 54: 123-130.

MARCELIS LFM 1996. Sink strength as a determinant of dry matter partitioning in the whole plant. Journal of Experimental Botany 47: 1281-1291.

PAPADOUPOULOS AP; PARARAJASINGHAM S. 1997. The influence of plant spacing on light interceptation and use in greenhouse tomato (Lycopersicon esculentum Mill.). A Review. Scentia Horticulturae 69: 1-29.

PARIS HS; NERSON H; BURGER Y; EDELSTEIN M; KARCHI Z. 1988. Synchrony of yield of melons as affected by plant type and density. J. Hortic. Sci. 63: 141147.

PEIL RMN. 2000. Radiación solar interceptada y crescimiento del pepino cultivado em NFT. Almería: Universidade de Almería. 210p. (Tese).

PEIL RMN; GALVÉZ JL. 2002a. Efffect of fruit removal on growth and biomass partitioning in cucumber. Acta Horticulturae 588: 69-74.

PEIL RMN; GALVÉZ JL. 2002b. Growth and biomass allocation to the fruits in cucumber: effect of plant density and arrangement. Acta Horticulturae 588: 75-80.

PEIL RMN; GALVÉZ JL. 2005. Reparto de materia seca como factor determinante de la producción de las hortalizas de fruto cultivadas em invernadero. Revista Brasileira Agrociência 11: 05-11.

SCHVAMBACH JL; ANDRIOLO JL; HELDWEIN AB. 2002. Produção e distribuição da matéria seca do pepino para conserva em diferentes populações de plantas. Ciência Rural 32: 35-41.

VALANTIN M; GARY C; VAISSIÈRI BE; FROSSARD JS. 1999. Effect of load on partitioning of dry matter and energy in Cantaloupe (Cucumis melo L.). Annals of Botany 84: 173-181. 